\title{
New Method of Residual Stress Evaluation and its Advantages in Comparison with More Common Hole-drilling Method
}

\author{
František Menda*, František Trebuňa, Patrik Šarga \\ Department of Applied Mechanics and Mechatronics, Faculty of Mechanical Engineering, Letná 9, 04200 Košice, Slovak Republic
}

\section{BIOGRAPHICAL NOTES}

Ing. František Menda (1989) successfully accomplished the high school with base on mathematics. Then he began studies at the Faculty of Mechanical Engineering of the Technical University of Košice. He graduated with honours a bachelor- degree study in Mechatronics in 2010 end continued an engineer degree study in same program. He defended his diploma thesis "Design of the conception for contactless control of air knives with drives for zincify production line no.3" in 2012 and accomplished this study with an honours. Nowadays, he is a PhD. student of Mechatronics and is concentrating on measuring of residual stress by Ring-core method.

Dr.h.c. mult. prof. Ing. František Trebuňa, CSc. his a professor of applied mechanics, Head of the Department of Applied Mechanics and Mechatronics, Director of the Institute of Special Technical Sciences and Vice-dean for development, external and internal relations. He is author of 9 monographs, 9 university textbook, special book publications, 12 university notebooks and more than 300 publications in journals and conference proceedings at Slovakia abroad. He is author of important projects and engineering works. He received several prizes at home and abroad. He received three honorary Doctor Honoris Causa (DHC) including two from foreign universities for the development of applied mechanics and mechatronics.

Ing. Patrik Šarga, PhD. (1979) He graduated in „Automation and Control in Mechanical Engineering" at Technical University of Košice in 2002. He was an internal PhD. student at the Department of Applied Mechanics and Mechatronics and in 2005 he defended his dissertation thesis in field of mechatronics. Nowadays he works as an assistant on the Department of Applied Mechanics and Mechatronics at the Faculty of Mechanical Engineering at Technical University of Košice. He is co-author of three books of lecture notes and more than 50 publications in journals and conference proceedings at Slovakia and abroad, e.g. Engineering Failure Analysis, Metalurgija. He has worked on several grant projects, research tasks and many projects solved for industry realized on the department.

\section{KEY WORDS}

Ring-Core, hole-drilling method, residual stresses.

\section{ABSTRACT}

Residual stress evaluation in constructions and mechanical parts is a necessary task in every modern industrial factory. Right evaluated changes in lifetime and loading con- 
ditions could save amount of money and increase the human safety. The Department of Applied Mechanics and Mechatronics has a long tradition in developing and practical usage of semi-destructive methods for determining residual stresses. Especially by using hole-drilling method and recently also Ring-Core method. Main characteristics and comparison of both methods with emphasis on Ring-Core analysis are discussed in this article.

\section{Introduction}

The lifetime prediction of every designing construction could be determined analytically using adequate equations from the theory of material strength by considering geometric parameters of the object and applied loads and deformations. During manufacturing procedures and machining processes like e.g. casting, stamping, grinding, shot peening or welding occur inside the materials specific state of stresses, which affect the total load capacity and the lifetime of investigated objects. Such inside stresses are called residual stresses and exist even without any external load. They also occur during production cycle, which could be extremely dangerous and unexpected. Insufficient attention devoted to the matter of residual stresses could in worst case lead to the destruction and costly repairs or even to danger of a human life. Therefore it is necessary to determine the magnitude, direction and sense of residual stresses acting in potentially risky parts of investigated object.

\subsection{Semi-destructive measuring methods}

Recently, there are various types of measuring methods for determining residual stresses inside the objects of interest. Generally they can be classified as follows: optical, acoustic, mechanical, roentgen, numerical methods.

This article deals more about mechanical methods. Mechanical methods evolved from rather cumbersome destructive methods, in which the tested object was totally destroyed, to semi-destructive methods, easily applicable in both laboratory and industrial conditions. Main advantage of semi-destructive method is its minimal effect on the working cycle and lifetime of tested object after measuring. The most common semi-destructive methods for residual stress determination are:

\section{- hole-drilling method,}

- Ring-Core method.

\section{Hole-drilling Method}

The hole-drilling method technique involves monitoring the change in stresses (or strains) produced when a hole is drilled into a component with residual stress. The dimensions of drilled hole are very small: both diameter and depth $1 \div 4 \mathrm{~mm}$. Therefore this method is only semi-destructive, the produced hole may be insignificant or repaired after testing. The change in strain may be measured on the top of specimen using photoelasticity, brittle- coating or electrical strain gages. Blind rather than through holes are used and reading of strain change is in various depths to assess the variation with depth. This allows us to create an idea of residual stress distribution along the specimen thickness. The hole is drilled into small depths because the residual stresses usually show up near the surface in form of cracks [1].

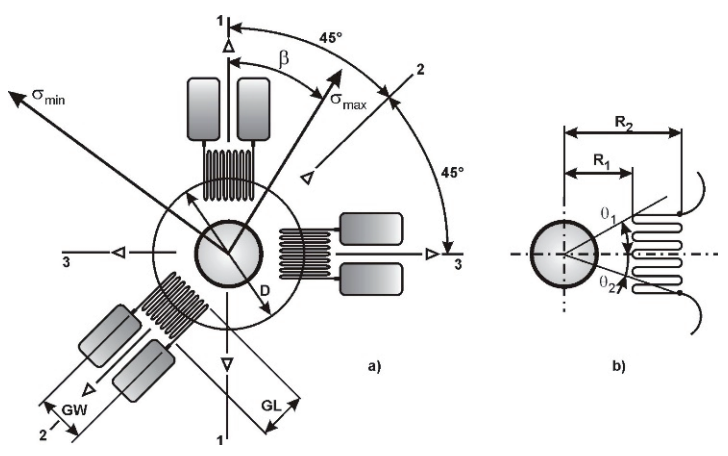

Fig. 1: Hole-drilling method.

For measuring revealed strain values on top of the specimen's surface we can use three basic types of strain gage rosettes defined by ASTM E 837 [2].

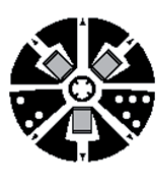

a)

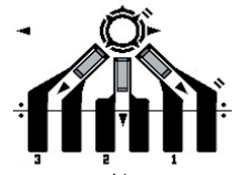

b)

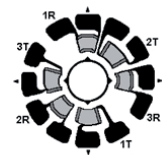

c)
Fig. 2: Types of strain gage rosettes [2].

\section{Type A:}

- Strain gage rosette for general using, e.g. RY61 made by HBM (Fig. 2a),

- Dimensions: $a=1,5 \mathrm{~mm}, b=0,8 \mathrm{~mm}, d=12 \mathrm{~mm}$, resistance $120 \Omega$. 


\section{Type B:}

- All grids are placed in one direction (Fig. 2b),

- This strain gage rosette is used for drilling near obstacle.

\section{Type C:}

- It is used for measuring strains with high sensitivity and in cases of high temperature stability (Fig. 2c),

- Rosette has three pairs of grids placed opposite each other which are connected to half bridge circuits.

The hole-drilling method is recently easily applicable and pretty precise method for evaluating residual stresses, defined by the standard ASTM E837-08 [3]. The Department of Applied Mechanics and Mechatronics has researched and developed the practical usage of this method for few decades. The most common device for experimental testing is RS200 (Fig. 3). This device consists of a simple stand for centering. Because it has no actuator, it requires a drill for making a hole. Static strain gage system P3500 connected with computer enables reading data values from strain gage rosette.

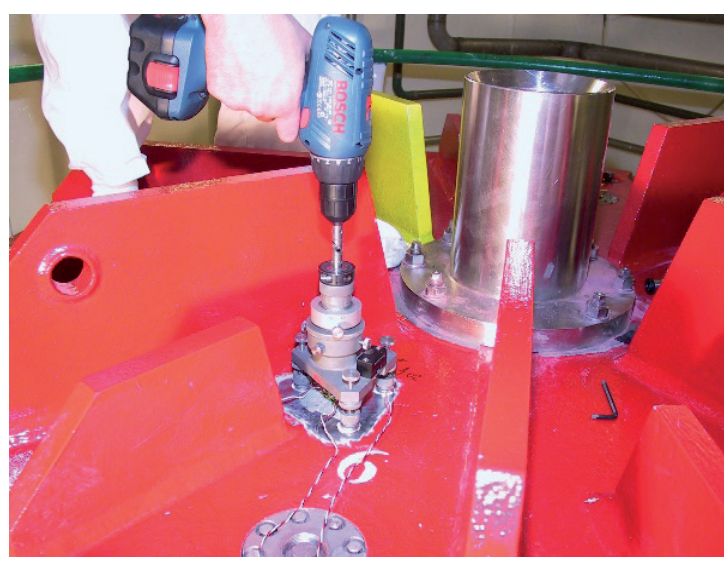

Fig. 3: RS200.

More sophisticated system is MTS 3000 produced by SINT (Fig. 4). I tis an automatic measuring system which is equiped by high-speed pneumatic turbine. The accuracy of positioning and centering is increased by build in microscope.

\section{Ring-Core method}

Ring-Core method is another semi-destructive method using for residual stress evaluation inside the material. This method improves some weaknesses of the hole-drilling method, but it brings more damage to the tested specimen. Similarly as in hole-drilling method, the principle is about attaching the special strain gage rosette to the specimen's surface. Instead of drilling a hole through the middle of the rosette, an annular notch is milled around the strain gage. This creates the isolated core, inside which the residual strains (stresses) relax. The dimensions of milled notch are: $14 \mathrm{~mm}$ inner and $18 \mathrm{~mm}$ outer diameter. The process of stress relieving is divided into small step increments up to maximum milling depth $5 \mathrm{~mm}$. Subsequently the distributions of residual stresses along the milled depth at specific investigated place are determined.

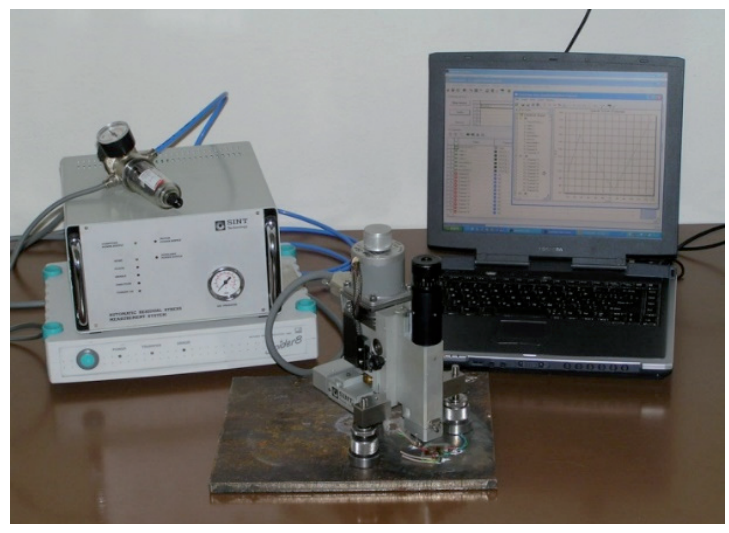

Fig. 4: MTS 3000.

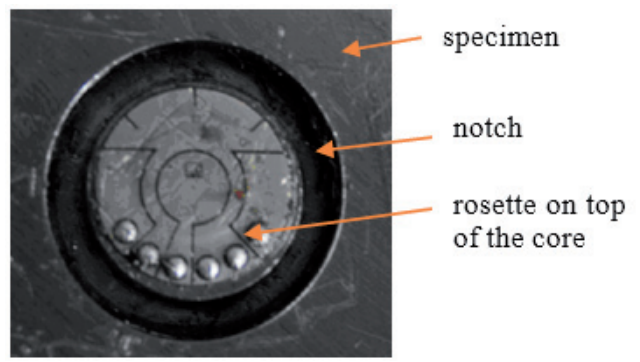

Fig. 5: Strain gage rosette for Ring-Core measurement after the milling.

XY51:

- It is used when directions of principal stresses are known (Fig. 6a),

- Dimensions: $a=5 \mathrm{~mm}, b=2,5 \mathrm{~mm}, c=12 \mathrm{~mm}$, electrical resistance $350 \Omega$.

RY51:

-It is used with unknown directions of principal stresses (Fig. 6b),

- Dimensions: $a=5 \mathrm{~mm}, b=2,5 \mathrm{~mm}, c=12 \mathrm{~mm}$, electrical resistance $350 \Omega$. 


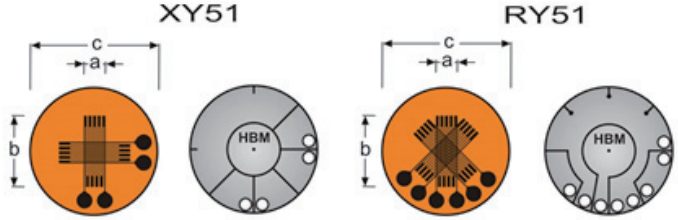

Fig. 6: Strain gage rosettes for Ring-Core method [2].

The Department of Applied Mechanics and Mechatronics owns fully automated measuring system MTS 3000 Ring-Core from SINT company. The system is designed for constant measuring and data evaluation during Ring-Core measuring procedure. Measuring string consists of mechanical unit for milling an annular notch, electronic control unit, digital strain gage amplifier (e.g. HBM Spider 8.30 or Quantum X) and computer with measuring and post-processing software. The mill positioning towards the strain gage rosette is provided by webcam in connection with utility Eyeshot.

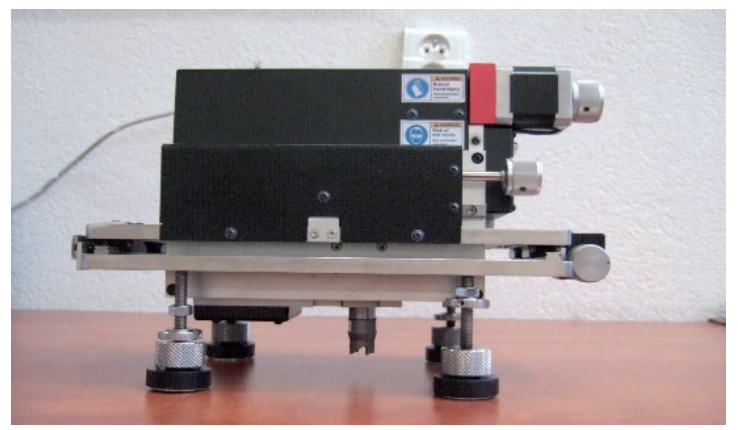

Fig. 7: SMTS 3000 Ring-Core.

Data cables from strain gage rosette are lead through the hollow mill and subsequently through the whole machine body. Such solution allows continuous data acquisition without the need of disconnecting and re-connecting cables. Especially problems with continuous data transfer during the precisely centered milling around the rosette slowed down the progress of the Ring-Core method. The Ring-Core method recently outmatches experimentally easier applicable hole-drilling method.

\section{Hole-drilling method versus Ring-Core method 4.1 Advantages of the Ring-Core method}

The Ring-Core method is comparing to the hole-drilling method younger in terms of practical applicability. Since both methods are based on similar principles, measuring procedure and the process of evaluation in Ring-Core method comes just from hole-drilling method, especially from the standard ASTM E837-08 [3]. Both methods are used due to their low costs, easy maintenance and applicability, sufficient accuracy and minimal specimen's damage. They are suitable for residual stress measurement in metals (ferromagnetic and non-ferromagnetic), ceramics, polymers and another homogenous materials, where linear elastic material behavior is expected. If it is needed to drill the hole into the standard steels by hole-drilling method, it is possible to use special high-speed drills and mills. When using Ring-Core method for milling into hard materials, it is possible to use mill, saw cutter or electrical discharge machining. Diamond tools could be used for drilling into very hard materials and also for drilling glass, ceramic or concrete specimens.

Another way of performing a hole/notch is by using a laser cut. The results are satisfied according to the created shape of a hole, but unsatisfied according to the temperature influencing around the hole. The laser beam of low intensity is not useful. Plastic deformations occurring near the hole boundaries could be microscopically detected. For that reason it is not recommended to use laser beam in combination with the methods used for measuring residual stresses.

Though both methods are similar (both methods consists of material removal in place of strain gage and subsequent measurement of deformation released from the nearby material), the most significant difference is in the shape of opening.

Hole-drilling method requires drilling a hole with the diameter $1 \div 4 \mathrm{~mm}$ through the middle of the rosette up to the depth equals to the hole diameter. By using Ring-Core method instead of drilled hole, annular notch with the diameter $14 \mathrm{~mm}$ is milled up to maximum depth $5 \mathrm{~mm}$, with the rosette placed in the middle on top of created core. Such measurement procedure release higher amount of deformations and the data signal is of the higher order. Ring-Core method is also not sensitive to temperature gradients near the milled notch.

The Ring-Core method is also more sufficient in cases of milling into coarse-grained materials like castings or welds. Measured objects should be more massive thus the annular notch is not close to the sharp geometric boundaries of the specimen. 
Too curved surfaces of investigated object could also make difficulties with right placing, measuring and evaluating according standard set of calibration coefficients. Milling to very thin specimen, respectively opening through whole thickness is by the nature of the method not possible.

Generally, the material removal procedures are carried in places, where during operating conditions the resulting opening will not act as an impermeable stress concentrator, or it can be removed by further processing operation.

\subsection{Disadvantages of the Ring-Core method}

The most significant disadvantages of the RigCore method in comparison with the hole-drilling method come from insufficient method development and no standardization of measuring and evaluation procedure. They are:

- the necessity to determine unique set of calibration coefficients (for uniform state of stress) respectively calibration factors (for non-uniform state of stress) in the dependence on mechanical parameters of measured material, geometric characteristics of the specimen and creating core, total milling depth, number and distribution of the steps and type of the strain gage rosette,

- limited applicability of the method and the necessity of respecting the factors affecting the accuracy of measurement,

- the possibility of affecting the state of stress inside the material by inadequate place of measurement.

\section{Evaluation of residual stresses components by the Ring-Core method [5], [6]}

The input parameters for residual stress determination in the dependence on the milling depth are:

- material properties: Young's modulus $E$ and Poisson's number $\mu$,

- three function curves of relieved strains $\left(\varepsilon_{1}, \varepsilon_{2}\right.$, $\left.\varepsilon_{3}\right)$ in the dependence on the changing depth, obtained from three measuring grids of strain gage rosette.

There are three common calculation methods for processing the input data:

- incremental method, suitable for uniform residual stress field,

- differential method, suitable for the easy view on uniform residual stress distribution along the specimen depth,
- integral method, suitable for non-uniform residual stress field.

\subsection{Incremental method}

Incremental method is based on the following assumptions:

- the strain (stress) increment is constant at each step of milling procedure,

- state of stress in particular step is not affected by the previous steps,

- stress in vertical direction (perpendicular to the strain gage surface) is negligible according to the strain values in plane of the strain gage rosette.

Principal residual stresses $\sigma_{1}$ and $\sigma_{2}$ are subsequently calculated according the following equations:

$$
\begin{aligned}
& \sigma_{1}=\frac{E}{K_{1}^{2}-\mu^{2} K_{2}^{2}} \cdot\left(K_{1} \frac{d \varepsilon_{1}}{d z}+\mu K_{2} \frac{d \varepsilon_{2}}{d z}\right) \\
& \sigma_{2}=\frac{E}{K_{1}^{2}-\mu^{2} K_{2}^{2}} \cdot\left(K_{1} \frac{d \varepsilon_{2}}{d z}+\mu K_{2} \frac{d \varepsilon_{1}}{d z}\right)
\end{aligned}
$$

Where $\mathrm{K}_{1}$ and $\mathrm{K}_{2}$ are calibration coefficients.

\subsection{Differential method}

Special type of incremental method is the differential method. For evaluating by this method there is needed to mill the final depth only in two steps. Subsequently there are only two sets of measured strain values. Therefore the size of difference $\Delta z$ consists of difference of two different milled depths zi and 2zi.

$$
\Delta \mathrm{z}=2 z_{i}-z_{i}=z_{i} \text {, pre } z_{i}=1,2,3,4 \mathrm{~mm} \text { (3) }
$$

Residual stresses are calculated according the following equations:

$$
\sigma_{1}=\frac{E}{K_{1}^{2}-\mu^{2} K_{2}^{2}} \cdot \frac{1}{\Delta z}\left(K_{1} \Delta \varepsilon_{1}+\mu K_{2} \Delta \varepsilon_{2}\right)
$$

$$
\sigma_{2}=\frac{E}{K_{1}^{2}-\mu^{2} K_{2}^{2}} \cdot \frac{1}{\Delta z}\left(K_{1} \Delta \varepsilon_{2}+\mu K_{2} \Delta \varepsilon_{1}\right)
$$

with:

$$
\begin{aligned}
& \Delta \varepsilon_{1}=\left(\varepsilon_{1}\right)_{2 z_{i}}-\left(\varepsilon_{1}\right)_{z i} \\
& \Delta \varepsilon_{2}=\left(\varepsilon_{2}\right)_{2 z_{i}}-\left(\varepsilon_{2}\right)_{z i}
\end{aligned}
$$

\subsection{Integral method}

Unlike the previous evaluation methods, integral method is based on assumption that each drilling step is influenced by the previous one. Therefore this method is suitable for calculating of non-uni- 
form residual stresses. Principal stresses $\sigma_{1 j}, \sigma_{2 j}$ in the $j$-th layer of milled notch, as a product of $i=1, . . n$ step increment are calculated:

$$
\begin{aligned}
& \sigma_{1 j}=\frac{1}{4}\left[\frac{\varepsilon_{\mathrm{aij}}+\varepsilon_{\mathrm{cij}}}{A_{\mathrm{ij}}}+\frac{\varepsilon_{\mathrm{aij}}-\varepsilon_{\mathrm{cij}}}{B_{\mathrm{ij}}}\right] \\
& \sigma_{2 \mathrm{j}}=\frac{1}{4}\left[\frac{\varepsilon_{\mathrm{aij}}+\varepsilon_{\mathrm{cij}}}{A_{\mathrm{ij}}}-\frac{\varepsilon_{\mathrm{aij}}-\varepsilon_{\mathrm{cij}}}{B_{\mathrm{ij}}}\right]
\end{aligned}
$$

Where $\varepsilon_{\text {aij, }} \varepsilon_{\mathrm{cij}}$ are strains read from strain gage rosette in principal directions and $\mathrm{A}_{\mathrm{ij}}$, $\mathrm{Bij}_{\mathrm{ij}}$ are calibration factors for integral evaluation method.

The disadvantage of integral method is complicated process of determining the calibration factors. Determining of set of both calibration coefficients for incremental method and calibration factors for integral method is researched by using simulations and finite elements method.

\section{An Experimental Example of Measuring Residual Stresses by the Ring-Core Method in Comparison to the Hole-drilling Method}

For verification of a new method in direct comparison with the hole-drilling method an experimental testing on appropriate specimen was done. To be sure of initial state of stress $\left(\sigma_{1}=45 \mathrm{MPa}\right.$, $\sigma_{2}=0 \mathrm{MPa}$ ) an annealed specimen (without any residual stress) of the thickness $10 \mathrm{~mm}$ was chosen and loaded by the loading machine. Material parameters of the tested specimen were: $\mathrm{E}=210 \mathrm{GPa}$, $\mu=0,3$. At the middle of the specimen the holedrilling method using system RS200 and at close place the Ring-Core method were used for residual stress measurement (Fig.8).

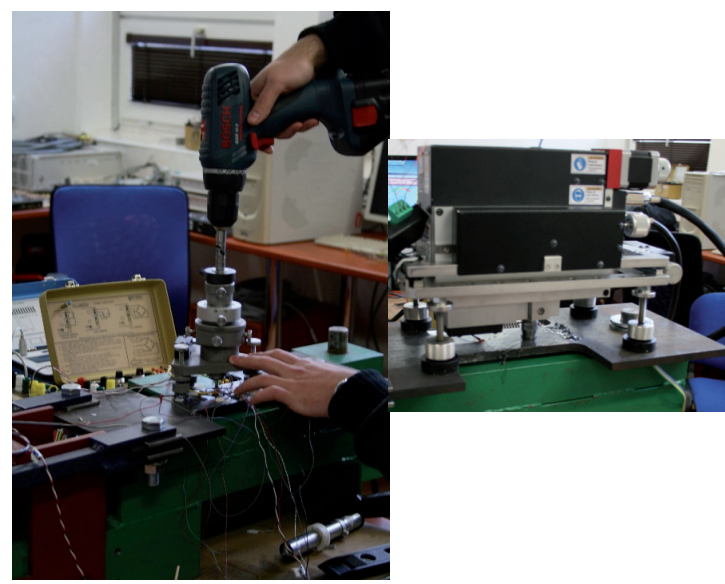

Fig. 8: left: hole-drilling, right: Ring-Core experimental testing.
The acquired results of evaluated residual stresses by both methods are in Fig. 9 and Fig.10.

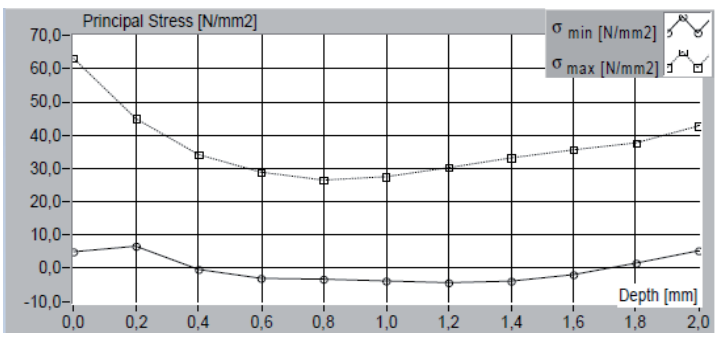

Fig. 9: Residual stresses evaluated by the hole-drilling method.

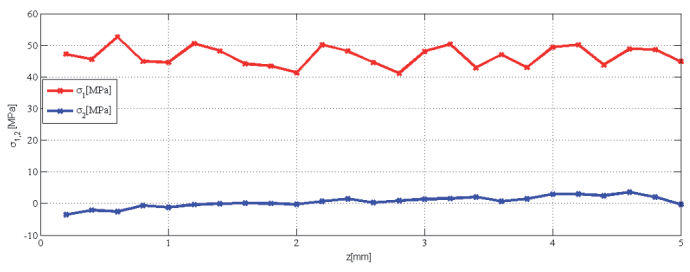

Fig. 10: Residual stresses evaluated by the Ring-Core method.

\section{Conclusion}

In the article there were described two semidestructive methods for evaluating residual stresses inside the materials, hole-drilling method and Ring-Core method. The Department of Applied Mechanics and Mechatronics has a long tradition of developing and practical usage of the hole-drilling method, which is recently most common semi-destructive method due to its easy applicability and standardized evaluation procedure. Ring-Core measuring method is in terms of usage and applicability relatively young method, which development is a part of research also at our department.

The primary task is to determine the universal set of calibration coefficients (factors) suitable for particular material characteristics and measuring strain gage rosette. The determination of these coefficients is provided using finite elements method in simulation software Solidworks and Ansys. Next, necessary step in development of the method is subsequent verification of acquired coefficients. Verification experiment has to be done on the specimen without any residual state of stress (annealed specimen), experimentally loaded using external loading device. Such procedure allows us to directly compare applied load with the experimentally evaluated state of stress.

After series of verification experiments with considering adequate influencing factors it will be pos 
sible to measure and evaluate any type of residual stress inside the investigated specimen by using system MTS 3000 Ring-Core.

\section{Acknowledge}

The authors would like to thank to Slovak Grant Agency - project VEGA 1/0937/12"Development of unconventional experimental methods for mechanic and mechatronic systems" and project FGV/2013/9 "Complex analysis of the Ring-Core method in order to create the evaluation program".

\section{References}

[1] F. Trebunna, F. Šimčák, Kvantifikácia zvyškových napätí tenzometrickýmu metódami, 1.vyd. Košice, TU, 2005. 134 p. ISBN 80-8073-227-2.

[2] Hottinger Baldwin Messtechnik GmbH - meracia technika, [online], http://www. hbm.com

[3] ASTM International Designation E 837-08: Standard Test Method for Determining Residual Stresses by the Hole-Drilling Strain Gauge Method, United States, 2008, 17 p.

[4] Masláková, K., 2012. Identification and quantification of influence of residual stresses on technical life of mechanical elements and systems by using Ring-core method, dissertation thesis, Košice.

[5] Valentini, E., Benincasa, A., Bertelli, A.: An Automatic System for Measuring ResidualStresses by the Ring-Core Method, In 40th National Convention, Palermo, Italy, September 2011.

[6] A. Civín, Komplexní teoretická analýza metody sloupku pro zjištování zbytkových napěttí, Brno: Vysoké učení technické v Brně, Fakulta strojního inženýrství, 2012. 130 p 